Research Article

\title{
Evaluation of Compression Behaviors of Marine Clay Reinforced with Waste Shredded Tires
}

\author{
Weijuan Geng $\left(\mathbb{D},{ }^{1}\right.$ Hao Liu, ${ }^{1}$ Jie Yin $\left(\mathbb{D},{ }^{1}\right.$ Yongwei Du, ${ }^{2}$ and Daniel Kumah ${ }^{1}$ \\ ${ }^{1}$ Department of Civil Engineering, Faculty of Civil Engineering and Mechanics, Jiangsu University, Zhenjiang 212013, China \\ ${ }^{2}$ Department of Civil Engineering, Zeda Vocational and Technical College, Suqian 223800, China \\ Correspondence should be addressed to Jie Yin; yinjie@ujs.edu.cn
}

Received 2 November 2021; Accepted 6 December 2021; Published 23 December 2021

Academic Editor: Bingxiang Yuan

Copyright (C) 2021 Weijuan Geng et al. This is an open access article distributed under the Creative Commons Attribution License, which permits unrestricted use, distribution, and reproduction in any medium, provided the original work is properly cited.

This study evaluates the compression behaviors of a soft marine clay reinforced with waste shredded tire (WST) at different sizes $(<0.5 \mathrm{~mm}, 0.5-2.0 \mathrm{~mm}$, and $2.0-4.0 \mathrm{~mm})$ and contents $(15 \%, 35 \%$, and $50 \%)$. Results from compression tests indicate that the compression index $\left(C_{c}\right)$ of WST-reinforced soft clay decreases with increasing WST shred size and content. The swelling index $\left(C_{s}\right)$ increases as the WST shred size and content increase. The difference in compression curves becomes more significant for composite reinforced at large shred size. The void indexes of WST-reinforced Lianyungang clay can be well normalized regardless of WST shred size and content by a regression line. The WST dominates the compression behavior of the WST-clay composite, as the WST would be compressed prior to the clay particles. The results in this study provide an optimum WST content at $50 \%$ with shred size of $2.0-4.0 \mathrm{~mm}$ for reinforcing the Lianyungang marine clay for achieving higher compressibility, contributing to the input database of machine learning for WST-reinforced soil.

\section{Introduction}

An estimate of over 1.4 billion waste tires are generated worldwide annually $[1,2]$ with the sharp increase in the number of vehicles in recent decades, and the number is at a growing rate of $2 \%$ per year. The waste tires from Europe, the United States, and Asia account for approximately $90 \%$ of the global waste tires [3,4]. For example, there were around 330 million waste tires with a weight of more than 10 million tons generated in China in the year 2019, and the growing rate of waste tires is at $6 \%-8 \%$ per year as per the latest report [5]. The enormous number of waste tires involves environmental impacts, as the stockpiled tires claim large areas of landfill; in addition, the waste tires would trigger fires releasing toxic gases, such as styrene, butadiene, $\mathrm{CO}, \mathrm{SO}_{2}$, $\mathrm{NO}$, and so on $[6,7]$, thus posing threat to human health. It is a worldwide challenge to recycle and to reduce the environmental pollution caused by waste tires.

The waste tires are shredded and reused as a reinforcement agent in the geotechnical application, e.g., subgrade backfilling, retaining wall, and landfill, since they are lightweight and cost effective with excellent durability [7-11]. A number of research studies have been conducted on mixing the waste shredded tires (WSTs) with soil, especially with coarse grain soils, to improve soil properties in shear strength and compressibility [12-23]. Soft clays are often with poor engineering properties, such as low permeability, high compressibility, and low strength [24-28]. In terms of WST reinforcement on fine-grain soils, controversial statements were found on the compression behaviors of soft clay reinforced with WST. For example, Li et al. [20] observed that the compression index of clay increased to a point and then decreased with increasing WST content. Pang [29] and Srivastava et al. [30] found a monotonic increasing trend in the compression index of clay with increasing WST content, while Ho et al. [31] and Yadav and Tiwari [32] stated that the compression index decreased as the WST content increased. The inconsistent findings indicate that that the compression index of WST-reinforced clay might depend on the WST shred size and can be altered by the type of clay. The proposed optimum WST content may not be applicable for reinforcing one targeted clay at a construction site.

This study aims to evaluate the compression behaviors of Lianyungang soft clay reinforced by WST. A series of 
compression tests were carried out on soft clay reinforced with WST at different shred sizes and contents. Results provide guidance for engineering applications (e.g., foundation and subgrade) of WST-reinforced clay in coastal areas, especially in the Lianyungang region. The optimum WST shred size and content are obtained for reinforcing marine soil, contributing to the input database of machine learning for WST-reinforced soil. In addition, a comparison was made between the compression behaviors of WST-reinforced Lianyungang clay and WST-reinforced clays from literature.

\section{Materials and Methods}

2.1. Marine Soil. The marine soil was collected from a construction site at Lianyungang Port, Jiangsu Province, China, by the coastline of the Yellow Sea. A polyvinyl chloride (PVC) tube with an inner diameter of $360 \mathrm{~mm}$ and height of $300 \mathrm{~mm}$ was used to obtain the site soil at the depth of $2.5 \mathrm{~m}$ below the ground surface to avoid the collection of soil affected by organic materials. The liquid limit and plastic limit of soil were $56.4 \%$ and $28.6 \%$, respectively, with a plasticity index of 27.8. Table 1 summarizes the basic properties of Lianyungang clay as per ASTM D422-63 (2007). Particle size analysis of marine soil is shown in Figure 1. Based on the Unified Soil Classification System (USCS), the soil is classified as clay of high plasticity $(\mathrm{CH})$.

2.2. Waste Shredded Tire(WST). The waste tires employed in this study were obtained from Huayi Rubber Co. (Dujiangyan, Sichuan, China). The waste tires were cut into shredded rubbers by a mechanical crusher at different shred sizes (average diameter) by a sieving process: $<0.5 \mathrm{~mm}$, 0.5-2.0 mm, and $2.0-4.0 \mathrm{~mm}$, as per ASTM D6270-17 (2017), as shown in Figure 2. The water content of rubber shreds is ignorable after air-drying. The specific gravity of WST is 1.3 , and the void ratio is 1.32 .

\subsection{Sample Preparation and One-Dimensional Compression} Test. The compression curve of natural soil is established based on those of the reconstructed soils at an initial water content of 1.0 and 1.5 times the liquid limit [33]. The marine soil was prepared at a water content of liquid limit (56.4\%) and then mixed with WST at targeted shred sizes (e.g., $<0.5 \mathrm{~mm}, 0.5-2.0 \mathrm{~mm}$, and $2.0-4.0 \mathrm{~mm}$ ) at the shred-to-soil ratio of $15 \%, 35 \%$, and $50 \%$ (by weight), respectively. A mechanical blender was employed to ensure homogeneous WST-soil samples. The mixed samples were then poured slowly into a cylindrical mold with an inner diameter of $61.8 \mathrm{~mm}$ and a height of $20 \mathrm{~mm}$.

One-dimensional compression tests were conducted on specimens by using a WG type oedometer (Nanjing Ningxi Instrument Co. Ltd.) as per ASTM D2435/D2435M-11 [34]. A series of incremental loads, i.e., 12.5, 25, 50, 100, 200, 400, and $800 \mathrm{kPa}$, were applied on soil specimens and then unloaded by steps $(800,400,200$, and $100 \mathrm{kPa})$ to $100 \mathrm{kPa}$, where each increment load was applied for $24 \mathrm{~h}$. The height of the specimen was recorded with each increment load after stabilization. A parafilm was employed to seal the specimen prior to loading to guarantee a constant water content in case of water evaporation. The specific gravity (equation (1)) and initial void ratio (equation (2)) of WST-reinforced soil are calculated by the following equations [35]:

$$
\begin{aligned}
G_{s t} & =\frac{1}{\chi / G_{t}+1-\chi / G_{s}}, \\
e_{0} & =\frac{(1+w) G_{s t} \rho_{w}}{\rho_{0}}-1,
\end{aligned}
$$

where $G_{\text {st }}$ is the specific gravity of WST-soil composite, $G_{s}$ is the specific gravity of soil, $\chi$ is the ratio of WST to WST-soil composite by weight, $\rho_{w}$ is the density of water taken as $1 \mathrm{~g} /$ $\mathrm{cm}^{3}, \rho_{0}$ is the initial density of WST-soil composite, and $w$ is the initial water content of the soil.

\section{Results and Discussion}

3.1. Effect of WST Shred Size and Content on Compression Behaviors of Marine Soil. Figure 3 shows the compression curves of Lianyungang marine soil reinforced at different WST contents with WST shred sizes of (a) $<0.5 \mathrm{~mm}$, (b) 0.5-2.0 $\mathrm{mm}$, and (c) $2.0-4.0 \mathrm{~mm}$ and those of WST-clay composites from literature. The addition of WST generally increases the compressibility of the Lianyungang clay regardless of the shred size, where the compression curves of WST-reinforced clay are located below those without reinforcement. A relatively large gap between the compression curves is observed for clays reinforced at 15\% WST and 35\% WST at all shred sizes. However, the WST-clay composite seems less compressible as the WST content increases from $35 \%$ to $50 \%$, especially with the composite reinforced at smaller WST shred size (Figure 3(a)). The difference in compression curves becomes more significant for composite reinforced at large shred size (Figure 3(b)).

The compression curves were also compared with those from Li et al. [35] on the WST-reinforced Qingdao clays at a similar water content, where the clay was reinforced with 2-4 $\mathrm{mm}$ WST at contents varying from $0 \%$ to $50 \%$ (Figure 3(c)). Those from Li et al. [35] were found to locate between the curves reinforced with WST at 15\% and 35\%, though a similar increasing compressibility trend was observed with increasing WST content. It suggests that the WST reinforcement is more significant in the compression behaviors on Lianyungang clay than that of Qingdao clay. Also, a threshold WST content was reported at 30\% reinforced with Qingdao clay, whereas no threshold content was yet found with Lianyungang clay at the shred size of 2-4 mm from $15 \%$ to $50 \%$. The difference in the effect of WST content on the compression behaviors of two marine clays suggests that the reinforcement efficiency may be altered by the intrinsic properties of marine clay, such as the liquid limit and the porewater chemistry.

Figure 4 presents the compression index (Figure 4(a)) and swelling index (Figure 4(b)) of WST-reinforced Lianyungang clay with WST content and those of WST-clay composites from literature. The compression index $\left(C_{c}\right)$ of WST-reinforced Lianyungang clay generally decreases with increasing WST content at all shred sizes. The decreasing 
TABLE 1: Basic properties of Lianyungang clay.

\begin{tabular}{lccccc}
\hline Water content $(\%)$ & Liquid limit $(\%)$ & Plastic limit $(\%)$ & Plasticity index & Unit weight $\left(\mathrm{kN} / \mathrm{m}^{3}\right)$ & Specific gravity \\
\hline $48.2-49.5$ & 56.4 & 28.6 & 27.8 & 17.8 & 2.71 \\
\hline
\end{tabular}

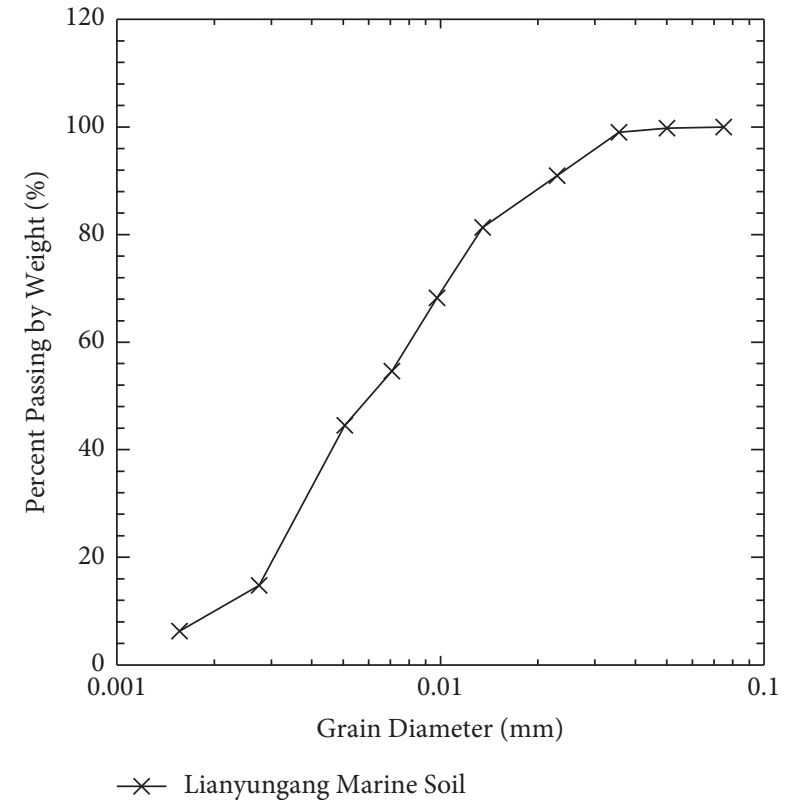

Figure 1: Grain size distribution of Lianyungang marine soil.

trend slightly levels off as the WST content becomes higher (e.g., $>35 \%$ ). Compared to $C_{c}$ reported from the literature, the changes in $C_{c}$ of Lianyungang clay are consistent with those reported by Ho et al. [31] and Yadav and Tiwari [32]. However, $C_{c}$ was found to increase with increasing WST content by Srivastava et al. [30] reinforced with both coarse $(2-4.75 \mathrm{~mm})$ and fine $(0.075-2 \mathrm{~mm})$ shreds. The inconsistency in $C_{c}$ of WST-soil composite reinforced with increasing WST content may be attributed to the type of clay used in the studies, where kaolinite and illite (LL at 34.2\%) were employed by Ho et al. [31] and Yadav and Tiwari [32], respectively, whereas Srivastava et al. [30] used an expansive black cotton soil with LL of $61 \%$. Signes et al. [36] conducted compression tests on clayey soil of similar LL (52.2\%); unfortunately, no clear trend was found on $C_{c}$. The obvious different behaviors in $C_{c}$ with varying WST content indicate that $C_{c}$ might depend on the intrinsic soil properties other than the liquid limit of clay.

Figure 4(b) plots the swelling index $\left(C_{s}\right)$ of WST-clay composite with WST content. $C_{s}$ increases fairly linear with increasing WST content at all shred sizes, suggesting a stronger elastic recovery of reinforced clay with higher content of WST. The results are in accordance with those reported in the literature (e.g., [36, 37]). Ho et al. [31] found a decreasing trend of $C_{s}$ with increasing WST, though with a scattered dataset, which may be due to the less rebounded rubber chips employed for reinforcement.

Figure 5 plots $C_{c}$ (Figure 5(a)) and $C_{s}$ (Figure 5(b)) in terms of WST shred sizes for Lianyungang soil in this study. At a given WST content, lower $C_{c}$ was obtained reinforced with a larger WST shred. The $C_{c}$ of WST-clay composite decreased $7.5 \%, 5.1 \%$, and $7.6 \%$ at WST content of $35 \%$, for example, reinforced with shred size at less than $0.5 \mathrm{~mm}$, $0.5-2.0 \mathrm{~mm}$, and $2.0-4.0 \mathrm{~mm}$, respectively. Meanwhile, $C_{s}$ increases with increasing WST shred size. It suggests that the WST was compressed prior to soil particles once under the pressure, and thus larger rubber shred may inhibit the compression of soil particles; upon unloading, the WST would also rebound before the soil particles, causing higher $C_{s}$ of WST-clay composite reinforced with larger shred size.

3.2. The Intrinsic Compression Line of WST-Reinforced Marine Soil. Burland [33] proposed an equation for defining the void index in the concept of intrinsic compression line (ICL), which describes the compression behaviors of reconstituted clays:

$$
I_{v}=\frac{e-e_{100}}{e_{100}-e_{1000}}
$$

where $e_{100}$ and $e_{1000}$ are the void ratios of clay at the consolidation pressure of $100 \mathrm{kPa}$ and $1000 \mathrm{kPa}$ in the consolidation test. A well-fitted line (equation (4)) for normalizing the reconstituted clay at a water content of 1.0 to 1.5 times the liquid limit was reported in terms of consolidation pressure $\left(\log \sigma_{\mathrm{v}}\right)$ in the range of $10 \mathrm{kPa}$ to $4000 \mathrm{kPa}$. Also, Ho et al. [31] proposed a correlated regression equation of intrinsic compression line under the consolidation pressure ranging from $1.5 \mathrm{kPa}$ to $1600 \mathrm{kPa}$ as the extended intrinsic compression line (EICL) as expressed in equation (5), where the EICL was fairly identical to ICL in the range of postsuction state $(>25 \mathrm{kPa})$.

$$
\begin{gathered}
I_{v}(\mathrm{ICL})=2.45-1.285 \log \sigma_{v}^{\prime}+0.015\left(\log \sigma_{v}^{\prime}\right)^{3}, \\
I_{v}(\mathrm{EICL})=3.0-1.87 \log \sigma_{v}^{\prime}+0.179\left(\log \sigma_{v}^{\prime}\right)^{2} .
\end{gathered}
$$

Figure 6 presents the normalized compression curves in terms of the void index and consolidation pressure for Lianyungang clay reinforced at different WST shred sizes and contents. The void indexes are well normalized regardless of WST shred size and content. For the points under low consolidation pressure $(<50 \mathrm{kPa})$, the void indexes in this study are smaller than those from Burland [33] and Ho et al. [31]. A regression equation was found to be well fitted to normalize the void index for WST-reinforced Lianyungang clay, as expressed in equation (6), with a coefficient of determination greater than 0.99 :

$$
I_{v}(\mathrm{WST}-\text { reinforced clay })=1.81-0.83 \log \sigma_{v}^{\prime}-0.0375\left(\log \sigma_{v}^{\prime}\right)^{2} .
$$

3.3. Discussion on the Compression Behaviors of WST-Reinforced Soil. The soil particle and water are considered imcompressible in Terzaghi's one-dimensional consolidation theory, where consolidation is a process of excluding water 


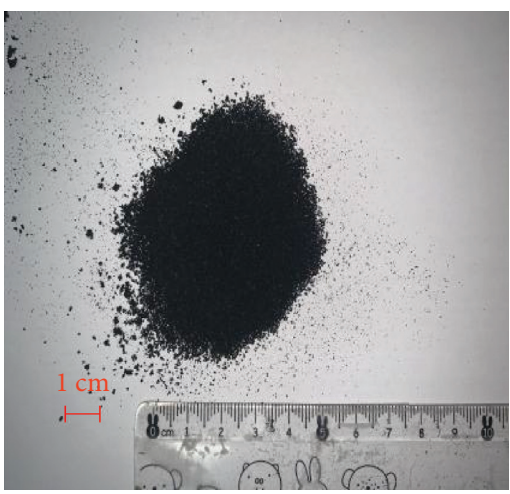

(a)

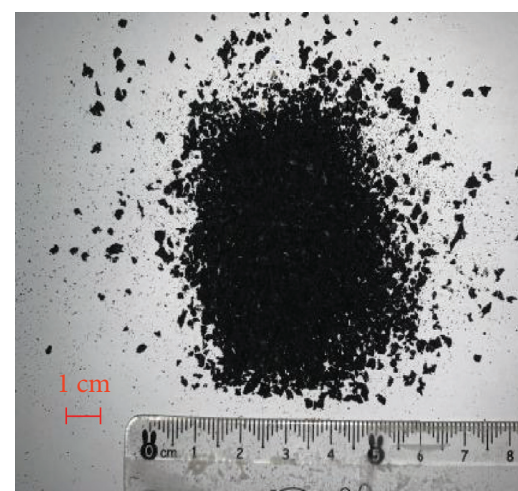

(b)

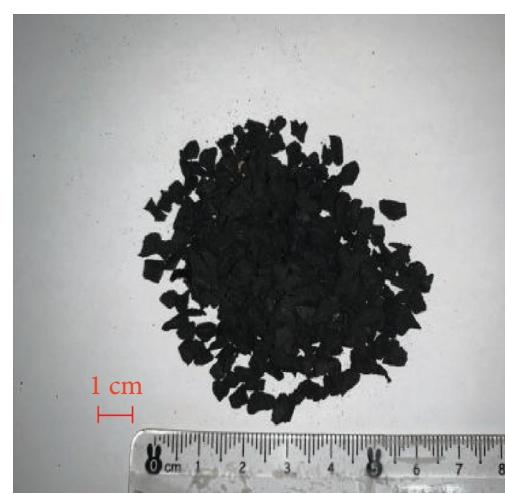

(c)

Figure 2: The waste tires are shredded in different sizes. (a) $<0.05 \mathrm{~mm}$. (b) $0.5-2 \mathrm{~mm}$. (c) $2-4 \mathrm{~mm}$.

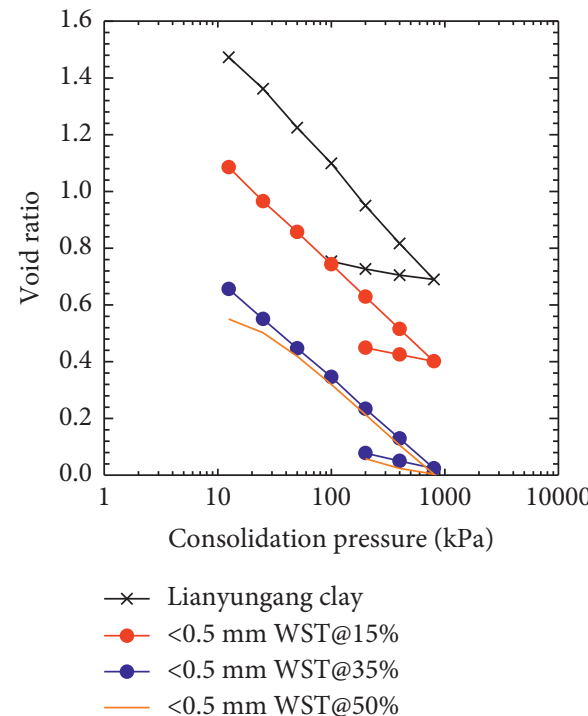

(a)

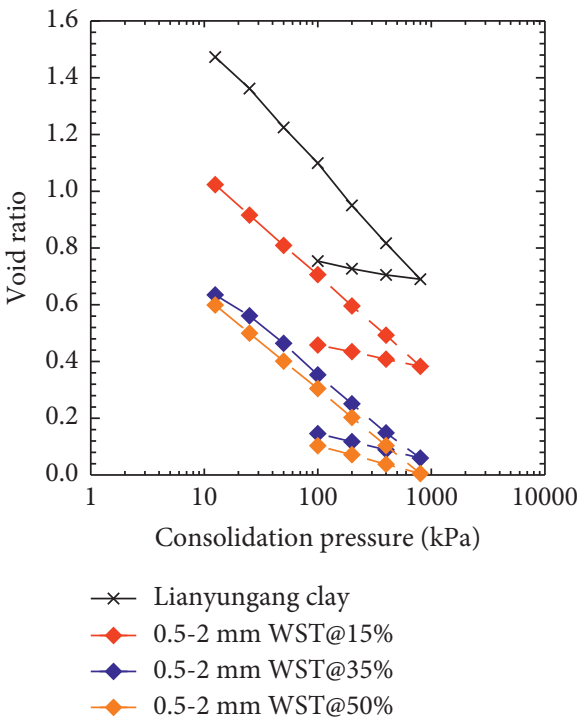

(b)

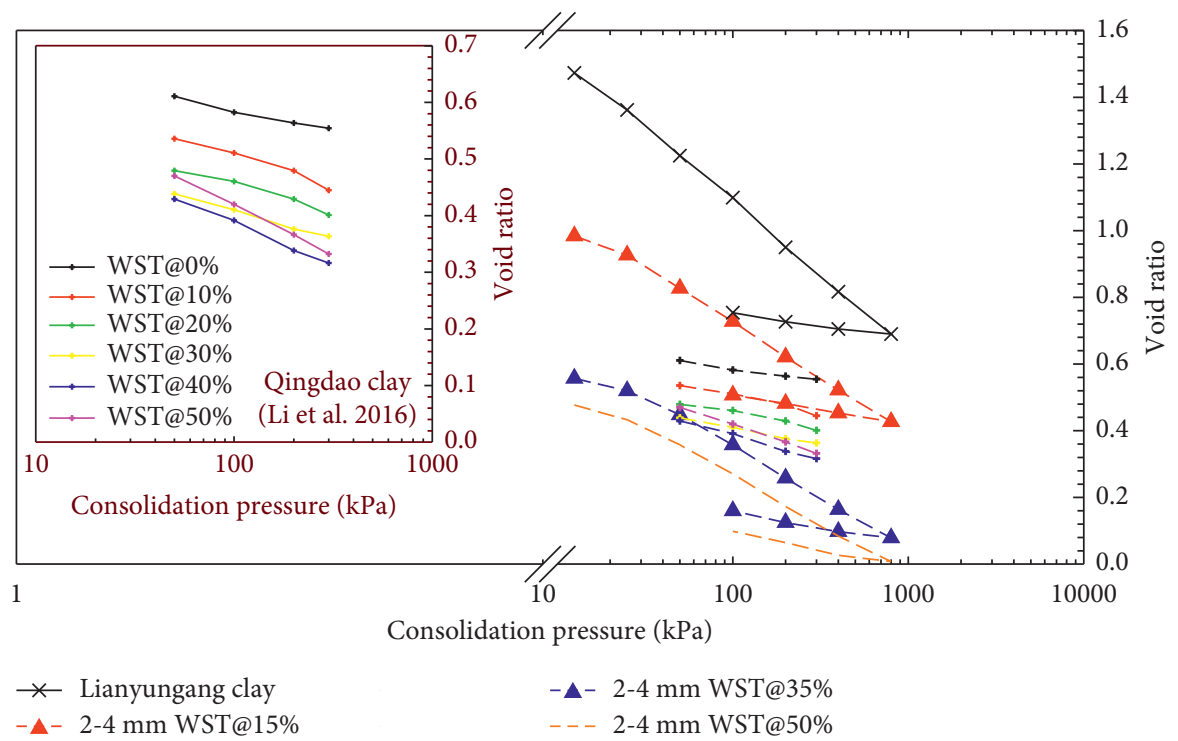

(c)

FIGURE 3: Compression curves of Lianyungang marine soil reinforced at different WST contents with shred sizes of (a) $<0.5 \mathrm{~mm}$, (b) $0.5-2.0 \mathrm{~mm}$, and (c) $2.0-4.0 \mathrm{~mm}$ and WST-clay composites from [20]. 


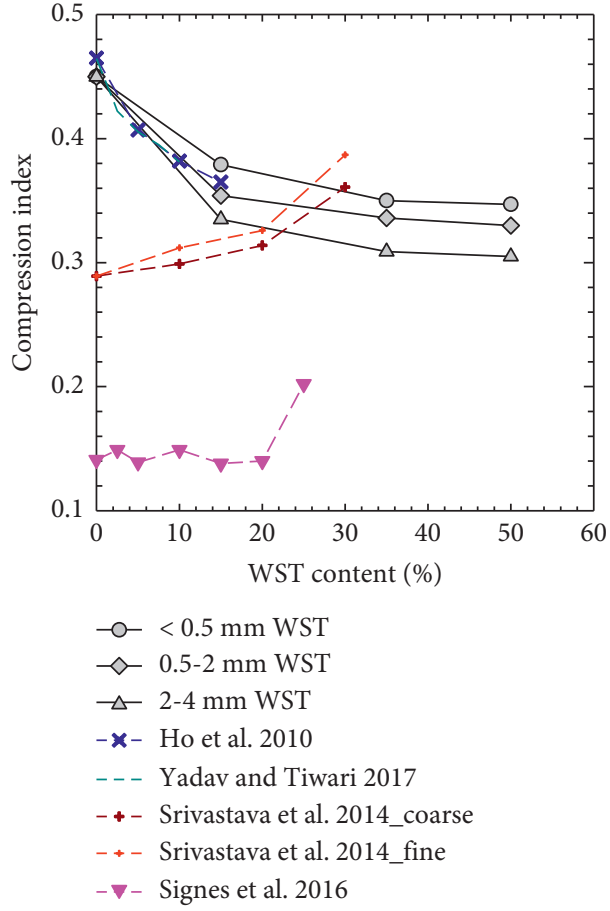

(a)

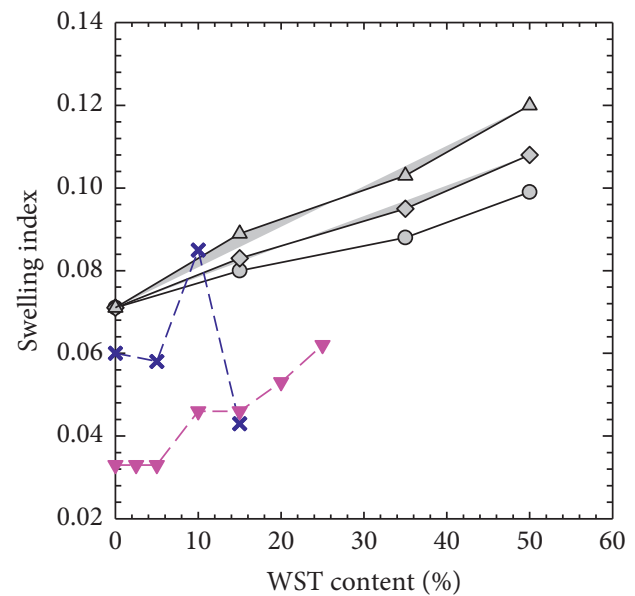

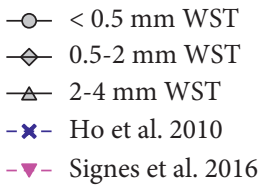

(b)

Figure 4: (a) Compression index and (b) swelling index of WST-reinforced clays with WST content.

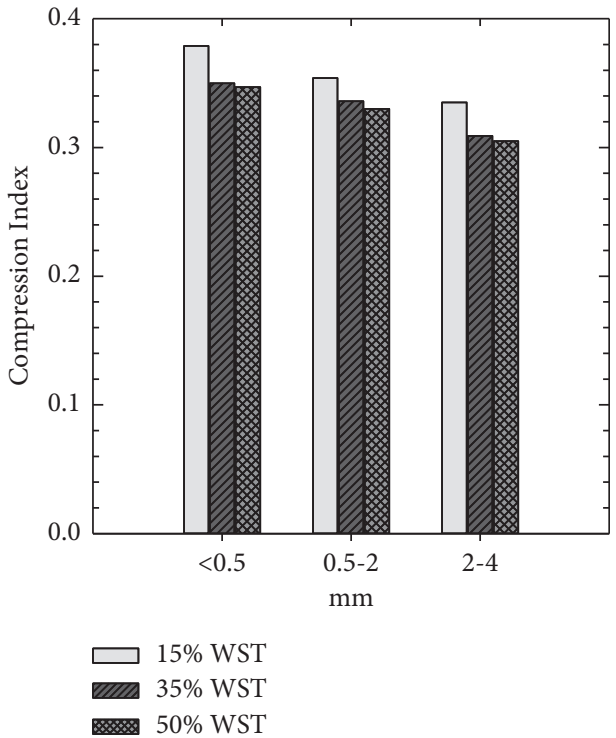

(a)

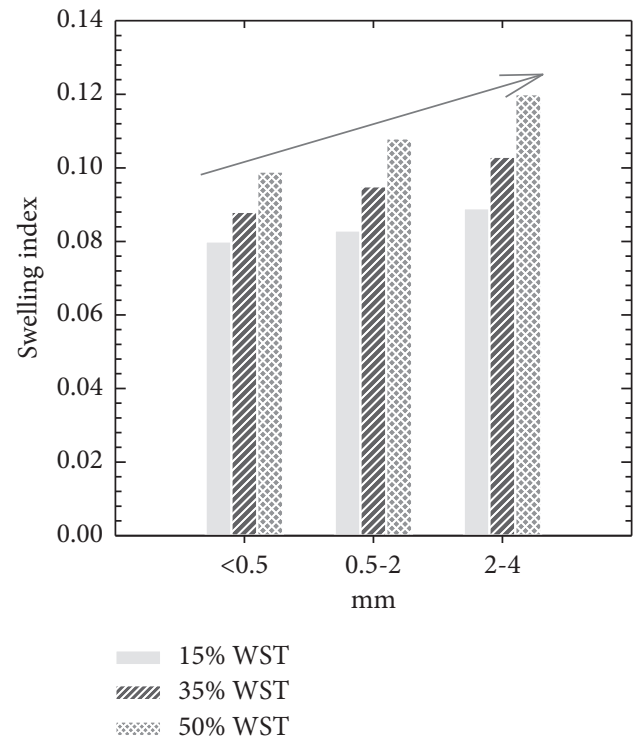

(b)

Figure 5: (a) Compression index and (b) swelling index of WST-reinforced Lianyungang marine soil.

from the soil pores while rearranging the soil aggregates. Upon consolidation, it would take a long time to exclude the water portion out of pores due to the low hydraulic conductivity of marine clay, where a tortuous flow channel may be presented $[25,38]$. The WSTs are surrounded by the clay aggregates in the WST-clay composite, as shown in scanning electron microscopy (SEM) analysis (Figure 7), the size of which is larger compared to the clay particles. In addition, the rubber tire shreds have higher elasticity and are more compressible than the clay particles. Thus, the WST would dominate the compression behaviors of the WST-clay composite.

A conceptual framework of WST-reinforced marine clay was created based on the laboratory observation from onedimensional compression tests and SEM image analysis (Figure 8). For marine clay without WST reinforcement, consolidation is a process of excluding water, where the 


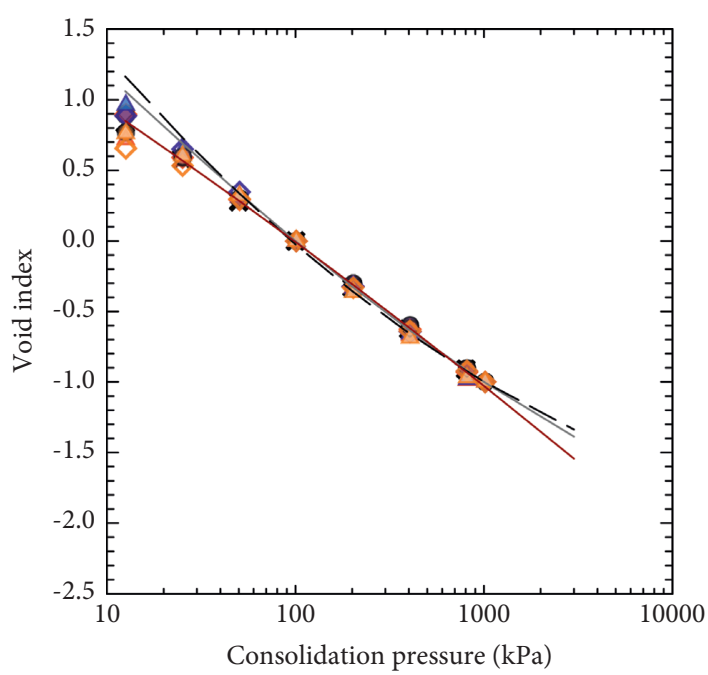

$$
\begin{array}{ll}
\mathbf{x} & \text { Without WST } \\
0 & <0.5 \text { WST@15\% } \\
\diamond & <0.5 \text { WST@35\% } \\
\Delta & <0.5 \text { WST@50\% } \\
0 & 0.5-2 \text { mm WST@15\% } \\
\diamond & 0.5-2 \text { mm WST@35\% } \\
\Delta & 0.5-2 \text { mm WST@50\% } \\
\bigcirc & 2-4 \text { mm WST@15\% } \\
\diamond & 2-4 \text { mm WST@35\% } \\
\Delta & 2-4 \text { mm WST@50\% } \\
- & \text { Burland (1990) } \\
--- & \text { Hong et al. (2010) } \\
- & \text { This study }
\end{array}
$$

FIgURE 6: Comparison of normalized compression curves with ICL and EICL.

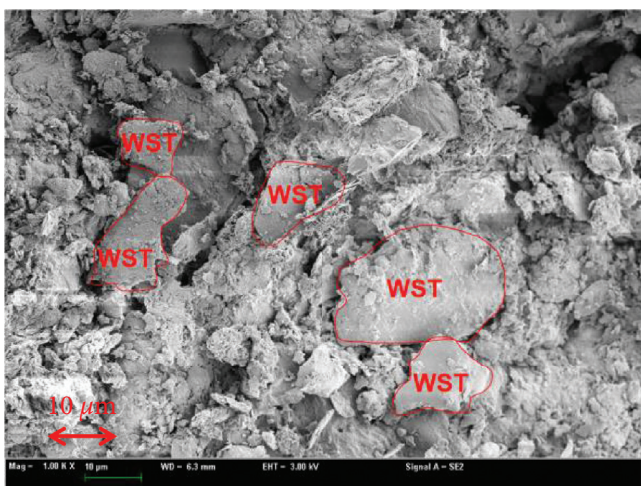

(a)

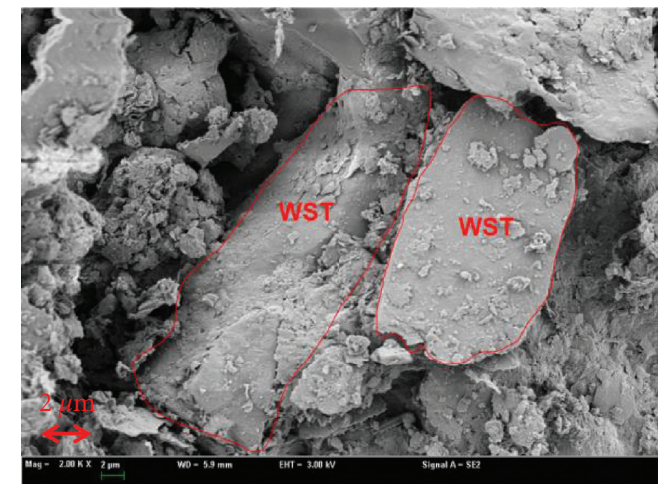

(b)

FIGURE 7: SEM images of WST-clay composite after compression test zooming at different scales.

volume change is the drainage of water since that of soil aggregate is fairly small within the $24 \mathrm{~h}$ loading duration (limited drainage in the intra-aggregate voids). Upon unloading, the rebound distance would be simply the swelling of clay particles. The WST can be compressed to an extent since the waste tire is an elastic material. Thus, the compressible range of WST-clay composite would be the displacement caused by the compressed WSTs in the matrix in addition to the expulsion of water. The rebound distance would be also larger due to the elastic behavior of WST in the unloading process.
With increasing WST content, WST dominates the compression behavior of WST-clay composite, as the WST would be compressed prior to the clay particles. As a result, an increased compression index would be obtained as more WSTs are added to the matrix. However, the volume of WST would not change, where the rubber shred has a flattened deformation under the vertical consolidation pressure (Figure 7(b)). Therefore, the increase in $C_{c}$ of WST-clay levels off with WST content till a threshold (Figure 4(a)). The WSTs would tend to recover their original shapes upon unloading with stronger rebound capacity, and thus higher $C_{s}$ would be consequently 


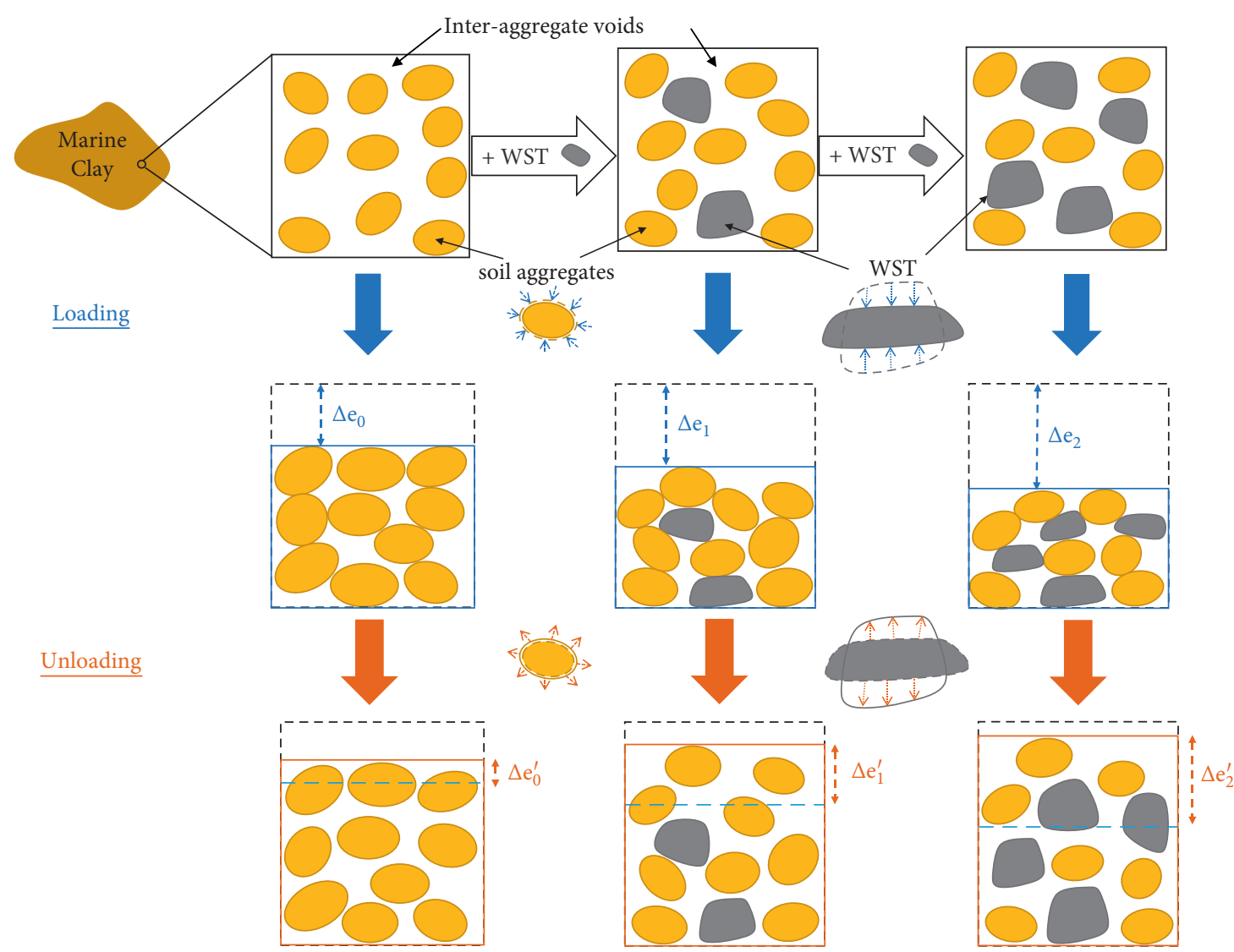

FIGURE 8: Schematic representation of WST-reinforced marine clay in loading and unloading processes (modified after [38]).

measured. Also, a larger shred size would contribute to more axial strain in both loading and unloading processes. Therefore, higher $C_{c}$ and $C_{s}$ were obtained with marine clay reinforced with larger WST (e.g., $2.0-4.0 \mathrm{~mm}$ ). However, soil fabric is strongly correlated with the porewater chemistry of marine clay, e.g., cation exchange capacity, salinity, etc., thus influencing $C_{c}$ and $C_{s}$ [39]; Yin et al. $[25,40]$. The mechanism underlying the effect of WST reinforcement on the fabric of marine clay needs to be further explored in the future.

\section{Summary and Conclusion}

This study experimentally evaluated the efficiency of WST reinforcement on the compression behaviors of Lianyungang marine clay under the effects of WST shred size and content and compared the results in this study to those from literature reinforced with other types of clays. A conceptual framework was proposed to understand the WST-clay interaction in the loading-unloading process by consolidation. The following conclusions are drawn based on the findings of this study:

(i) The compression curves of WST-reinforced clays exhibit similar trends regardless of WST content. The difference in compression curves becomes more significant for composite reinforced at large shred size. The compression index of WST-reinforced Lianyungang clay generally decreases with increasing
WST content and shred size, while the swelling index increases as the WST content and shred size increase.

(ii) The void indexes can be well normalized regardless of WST shred size and content. Under the low consolidation pressure, the void index in this study is different from ICL and EICL curves. A regression curve was found to be well fitted to normalize the void index for WST-reinforced Lianyungang clay.

(iii) It is proposed that the WST dominates the compression behavior of WST-clay composite, as the WST would be compressed prior to the clay particles, contributing a threshold WST content for reinforcing the marine clay. Also, the compressibility would be more significantly influenced by the WST at larger sizes.

(iv) The optimum WST content at $50 \%$ with a shred size of $2.0-4.0 \mathrm{~mm}$ is recommended for reinforcing the Lianyungang marine clay for higher compressibility, in coastal engineering applications such as subgrade. The difference in compressibility of WST-reinforced clay may be attributed to the intrinsic properties of soil, such as porewater chemistry. The results in this study contribute to the input database of machine learning for WSTreinforced soil. However, the mechanism underlying the evolution of soil fabric under the effect of 
WST reinforcement for marine clay is needed in the future [41-43].

\section{Data Availability}

All data, models, and codes that support the findings of this study are available from the corresponding author upon reasonable request.

\section{Disclosure}

The opinions, findings, conclusions, or recommendations expressed herein are those of the authors and do not necessarily represent the views of the sponsor.

\section{Conflicts of Interest}

The authors declare that they have no conflicts of interest.

\section{Acknowledgments}

We gratefully appreciate the financial support from the National Natural Science Foundation of China (no. 51978315).

\section{References}

[1] M. Sienkiewicz, J. Kucinska-Lipka, H. Janik, and A. Balas, "Progress in used tyres management in the European Union: a review," Waste Management, vol. 32, no. 10, pp. 1742-1751, 2012.

[2] L. Zeng and A. Ramaswami, "Impact of Locational Choices and Consumer Behaviors on Personal Land Footprints: An Exploration Across the Urban-Rural Continuum in the United States," Environmental Science \& Technology, vol. 54, no. 6, pp. 3091-3102, 2020.

[3] M. E. Boesch, A. Koehler, and S. Hellweg, "Model for cradleto-gate life cycle assessment of clinker production," Environmental Science \& Technology, vol. 43, no. 19, pp. 75787583, 2009.

[4] I. Järlskog, A.-M. Strömvall, K. Magnusson et al., "Occurrence of tire and bitumen wear microplastics on urban streets and in sweepsand and washwater," Science of The Total Environment, vol. 729, p. 138950, Article ID 138950, 2020.

[5] X. Han, "Waste tires become "black gold"," Resource Recycling, vol. 2021, no. 7, pp. 21-22, 2020, (in chinese).

[6] Y. W. Yoon, S. B. Heo, and K. S. Kim, "Geotechnical performance of waste tires for soil reinforcement from chamber tests," Geotextiles and Geomembranes, vol. 26, no. 1, pp. 100-107, 2008.

[7] S. N. Moghaddas Tafreshi and A. H. Norouzi, "Bearing capacity of a square model footing on sand reinforced with shredded tire - An experimental investigation," Construction and Building Materials, vol. 35, pp. 547-556, 2012.

[8] M. Neaz Sheikh, M. Mashiri, J. Vinod, and H.-H. Tsang, "Shear and compressibility behavior of sand-tire crumb mixtures," Journal of Materials in Civil Engineering, vol. 25, pp. 1366-1374, 2012.

[9] L. Liu, G. Cai, and S. Liu, "Compression properties and micromechanisms of rubber-sand particle mixtures considering grain breakage," Construction and Building Materials, vol. 187, pp. 1061-1072, 2018.
[10] Y.-s. Shen, Y. Tang, J. Yin, M.-p. Li, and T. Wen, “An experimental investigation on strength characteristics of fiberreinforced clayey soil treated with lime or cement," Construction and Building Materials, vol. 294, no. 1-2, p. 123537, Article ID 123537, 2021.

[11] B. Yuan, Z. Li, Y. Chen et al., "Mechanical and microstructural properties of recycling granite residual soil reinforced with glass fiber and liquid-modified polyvinyl alcohol polymer," Chemosphere, vol. 286, p. 131652, Article ID 131652, 2022.

[12] A. Edinçliler and V. Ayhan, "Influence of tire fiber inclusions on shear strength of sand," Geosynthetics International, vol. 17, no. 4, pp. 183-192, 2010.

[13] M. F. Attom, "The use of shredded waste tires to improve the geotechnical engineering properties of sands," Environmental Geology, vol. 49, no. 4, pp. 497-503, 2006.

[14] T. Tanchaisawat, D. T. Bergado, P. Voottipruex, and K. Shehzad, "Interaction between geogrid reinforcement and tire chip-sand lightweight backfill," Geotextiles and Geomembranes, vol. 28, no. 1, pp. 119-127, 2010.

[15] H. Sellaf, H. Trouzine, M. Hamhami, and A. Asroun, "Geotechnical properties of rubber tires and sediments mixtures," Engineering, Technology \& Applied Science Research, vol. 4, no. 2, pp. 618-624, 2014.

[16] M. Hyodo, S. Yamada, R. Orense, M. Okamoto, and H. Hazarika, "Undrained cyclic shear properties of tire chipsand mixtures," in Proceedings of the international workshop on scrap tire derived geomaterials-opportunities and challenges, pp. 187-196, Yokosuka, Japan, March 2007.

[17] T. Uchimura, N. Chi, S. Nirmalan, T. Sato, M. Meidani, and I. Towhata, "Shaking table tests on effect of tire chips and sand mixture in increasing liquefaction resistance and mitigating uplift of pipe," in Proceedings of the international workshop on scrap tire derived geomaterials-opportunities and challenges, pp. 179-186, Yokosuka, Japan, January 2007.

[18] T. Kaneko, R. P. Orense, M. Hyodo, and N. Yoshimoto, "Seismic response characteristics of saturated sand deposits mixed with tire chips," Journal of Geotechnical and Geoenvironmental Engineering, vol. 139, no. 4, pp. 633-643, 2013.

[19] M. S. Mashiri, J. S. Vinod, and M. N. Sheikh, "Liquefaction potential and dynamic properties of sand-tyre chip (STCh) mixtures," Geotechnical Testing Journal, vol. 39, no. 1, pp. 20150031-79, 2016.

[20] B. Li, M. Huang, and X. Zeng, "Dynamic behavior and liquefaction analysis of recycled-rubber sand mixtures," Journal of Materials in Civil Engineering, vol. 28, no. 11, Article ID 04016122, 2016.

[21] P. Promputthangkoon and A. F. L. Hyde, "Compressibility and liquefaction potential of rubber composite soils," in Proceedings of the international workshop on scrap tire derived geomaterials-opportunities and challenges, pp. 161-170, Yokosuka, Japan, January 2007.

[22] N. Shariatmadari, M. Karimpour-Fard, and A. Shargh, "Evaluation of Liquefaction Potential in Sand-Tire Crumb Mixtures Using the Energy Approach," International Journal of Civil Engineering, vol. 17, no. 2, pp. 181-191, 2019.

[23] L. Liu, G. Cai, J. Zhang, X. Liu, and K. Liu, "Evaluation of engineering properties and environmental effect of recycled waste tire-sand/soil in geotechnical engineering: a compressive review," Renewable and Sustainable Energy Reviews, vol. 126, p. 109831, Article ID 109831, 2020.

[24] J. Yin, M.-m. Hu, G.-z. Xu, W.-x. Han, and Y.-h. Miao, "Effect of salinity on rheological and strength properties of cementstabilized clay minerals," Marine Georesources \& Geotechnology, vol. 38, no. 5, pp. 611-620, 2020. 
[25] J. Yin, Z. Lu, W. Geng, W. Han, and A. A. Hudu, "Effect of porewater salinity on compression behaviors and hydraulic conductivity of soft marine clay," Marine Georesources \& Geotechnology, pp. 1-10, 2021.

[26] G. Xu, Y. Gao, J. Yin, R. Yang, and J. Ni, "Compression behavior of dredged slurries at high water contents," Marine Georesources \& Geotechnology, vol. 33, no. 2, pp. 99-108, 2015.

[27] G.-z. Xu and J. Yin, "Compression behavior of secondary clay minerals at high initial water contents," Marine Georesources \& Geotechnology, vol. 34, no. 8, pp. 721-728, 2016.

[28] U. Khalid, G.-1. Ye, S. K. Yadav, A. Zhou, and L. Gu, "Consolidation pressure consequences on the soil structure of artificial structured marine clay: macro and micro evaluation," Geotechnical and Geological Engineering, vol. 39, no. 1, pp. 247-263, 2020.

[29] B. H. Pang, Study on Engineering Characteristics of Guilin Red Clay Improved by Waste Tire Rubber Particles. Dissertation, Guilin University of Technology, Guilin, China, (in Chinese), 2020.

[30] A. Srivastava, S. Pandey, and J. Rana, "Use of shredded tyre waste in improving the geotechnical properties of expansive black cotton soil," Geomechanics and Geoengineering, vol. 9, no. 4, pp. 303-311, 2014.

[31] M. H. Ho, C. M. Chan, and I. Bakar, "One dimensional compressibility characteristics of clay stabilised with cementrubber chips," International Journal of Sustainable Construction Engineering and Technology, vol. 1, no. 2, pp. 91-104, 2010.

[32] J. S. Yadav and S. K. Tiwari, "A study on the potential utilization of crumb rubber in cement treated soft clay," Journal of Building Engineering, vol. 9, pp. 177-191, 2017.

[33] J. B. Burland, "On the compressibility and shear strength of natural clays," Géotechnique, vol. 40, no. 3, pp. 329-378, 1990.

[34] Astm D2435/D2435M-11, "Test Methods for One-Dimensional Consolidation Properties of Soils Using Incremental Loading," Standard Test Methods for One-Dimensional Consolidation Properties of Soils Using Incremental Loading, ASTM International, West Conshohocken, PA, USA, 2020.

[35] S. Li, D. Li, and Y. Zhang, "Influence of the content of waste tire particles on the compression characteristics of cohesive soil," Journal of Shandong University of Science and Technology, vol. 35, no. 5, pp. 55-62, 2016, (in chinese).

[36] C. Hidalgo Signes, J. Garzón-Roca, P. Martínez Fernández, M. E. Garrido de la Torre, and R. Insa Franco, "Swelling potential reduction of Spanish argillaceous marlstone facies tap soil through the addition of crumb rubber particles from scrap tyres," Applied Clay Science, vol. 132-133, pp. 768-773, 2016.

[37] H. Pincus, T. Edil, and P. Bosscher, "Engineering properties of tire chips and soil mixtures," Geotechnical Testing Journal, vol. 17, no. 4, pp. 453-464, 1994.

[38] W. Geng, Assessing the performance of polymer-bentonite mixtures for hydraulic barrier applications, $\mathrm{PhD}$ thesis, University of Wisconsin, Madison, WI, USA, 2018.

[39] D. Tessier, "Behaviour and microstructure of clay minerals," NATO ASI Series. In Soil Colloids and Their Associations in Aggregates, Plenum Press, New York, NY, USA, pp. 387-415, 1990.

[40] W. J. Likos and N. Lu, "Pore-scale analysis of bulk volume change from crystalline interlayer swelling in $\mathrm{Na}+-$ and $\mathrm{Ca} 2+-$ smectite," Clays and Clay Minerals, vol. 54, no. 4, pp. 515-528, 2006.

[41] H. Y. Lei, B. Li, H. B. Lu, and Q. Ren, "Dynamic deformation behavior and cyclic degradation of ultrasoft soil under cyclic loading," Journal of Materials in Civil Engineering, vol. 28, no. 11, Article ID 04016135, 2016.

[42] M. A. Sakr, M. A. Shahin, and Y. M. Metwally, "Utilization of lime for stabilizing soft clay soil of high organic content," Geotechnical and Geological Engineering, vol. 27, no. 1, pp. 105-113, 2009.

[43] Astm D6270-08, "Practice for use of scrap tires in civil engineering applications," Standard Practice for Use of Scrap Tires in Civil Engineering Applications, ASTM International, West Conshohocken, PA, USA, 2012. 